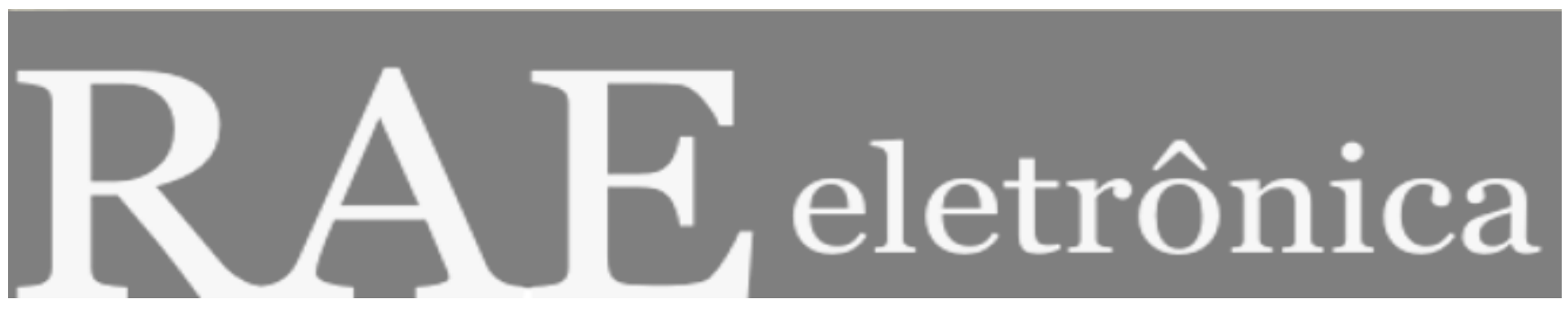

\title{
"ADMINISTRAÇÃO COMPLEXA": REVENDO AS BASES CIENTÍFICAS DA ADMINISTRAÇÃO
}

Por:

\section{Marcia Cristina Esteves Agostinho}

RAE-eletrônica, Volume 2, Número 1, jan-jun/2003.

http://www.rae.com.br/eletronica/index.cfm?FuseAction=Artigo\&ID=1254\&Secao=ORGANIZA\&Volume=2\&Numero=1 $\& A n o=2003$

CCopyright, 2002, RAE-eletrônica. Todos os direitos, inclusive de tradução, são reservados. É permitido citar parte de artigos sem autorização prévia desde que seja identificada a fonte. A reprodução total de artigos é proibida. Os artigos só devem ser usados para uso pessoal e não-comercial. Em caso de dúvidas, consulte a redação: redacao@rae.com.br.

A RAE-eletrônica é a revista on-line da FGV-EAESP, totalmente aberta e criada com o objetivo de agilizar a veiculação de trabalhos inéditos. Lançada em janeiro de 2002, com perfil acadêmico, é dedicada a professores, pesquisadores e estudantes. Para mais informações consulte o site www.rae.com.br/eletronica.

RAE-eletrônica

ISSN 1676-5648

(C2002 Editora: Fundação Getulio Vargas - Escola de Administração

de Empresas de São Paulo.
F U N D A C Ã 0 GETULIO VARGAS

Escola de Administração de Empresas de São Paulo 


\section{"ADMINISTRAÇÃO COMPLEXA": REVENDO AS BASES CIENTÍFICAS DA ADMINISTRAÇÃO}

\section{Marcia Cristina Esteves Agostinho}

Doutora em Engenharia de Produção pela COPPEAD/UFRJ

E-mail: marciaagostinho@aol.com

Endereço: Departamento de Engenharia Industrial - PUC-Rio - R. Marquês de São Vicente 225, Rio de Janeiro, RJ 22453-900.

Interesses de pesquisa: Complexidade, Sistemas Organizacionais, Organização da Produção, Processos de Tomada de Decisão, Redes Inter-organizacionais

\section{RESUMO}

Este artigo aponta a Teoria da Complexidade como uma nova base conceitual capaz de readequar a prática administrativa ao ambiente organizacional contemporâneo. Neste sentido, é apresentada a "Administração Complexa" - uma abordagem gerencial que leva para o universo das organizações os conhecimentos oriundos desta nova ciência. Com base no funcionamento dos chamados "sistemas complexos adaptativos", são estabelecidos quatro conceitos-chave: autonomia, cooperação, agregação e auto-organização. Estes são sugeridos como os princípios da "Administração Complexa". Com o objetivo de demonstrar a abordagem, é apresentado um estudo de caso realizado em uma organização industrial brasileira, a qual desenvolveu um sistema de gestão autônoma em uma de suas fábricas. Tal sistema ilustra o novo papel da administração que, ao deixar de se concentrar na prescrição e no controle, passa à tarefa de promover as condições para que desempenhos superiores possam surgir da atuação de indivíduos autônomos.

\section{ABSTRACT}

This paper suggests the Complexity Theory as being a new conceptual basis that is capable of adapting administration to the kind of environment that contemporary organizations deal with. Then, a management approach - "Complex Administration" - is presented that aims at bringing the knowledge from this new science to the organizational universe. Based on the so called "complex adaptive systems", the key-concepts for our approach are established. Therefore, autonomy, cooperation, aggregation and self-organization are suggested as principles of "Complex Administration". Hopefully, by focusing on these four points, managers will be able to accomplish their task of influencing organizational performance. Aiming at demonstrating our approach, we present a case study carried out in a Brazilian industrial organization, which had developed an autonomous management system in one of its plants. This system illustrates the new role played by manager, who goes from commanding and controlling to autonomous individuals coaching.

\section{PALAVRAS-CHAVE}

Complexidade, administração, autonomia, cooperação, auto-organização.

\section{KEY WORDS}

Complexity, management, autonomy, cooperation, self-organization. 


\section{INTRODUÇÃO}

Há algum tempo, é possível notar que o controle rigoroso de uma organização é impraticável. Tamanho é o número de relações - internas e externas, propiciadas por sistemas de comunicação capazes de interligar os mais distantes e distintos indivíduos - que é impossível saber os resultados de todas as interações e combinações possíveis. Cada vez mais os limites de uma ação gerencial clássica tornam-se evidentes: dificuldade ou impossibilidade de planejamento e controle totais, limites cognitivos à racionalidade e mesmo o processo de complexificação do mundo.

Entretanto, a nova ciência da Complexidade pode trazer um grande alívio para os administradores ao mostrar a mais interessante característica dos "sistemas complexos adaptativos": a capacidade de auto-organização. Se as organizações humanas também fazem parte desta categoria de sistemas, os administradores podem contar com este potencial. Ao mesmo tempo que a Teoria da Complexidade diz que não adianta insistir em controlar um sistema complexo de cima, ela acena com a possibilidade de aprender maneiras para promover condições que propiciem a emergência de melhores soluções.

É por essa razão que a última década testemunhou um esforço crescente em trazer os resultados das pesquisas sobre sistemas complexos para a economia e para o universo das organizações. Tanto a literatura estrangeira como a nacional têm refletido este esforço no considerável número de obras publicadas a esse respeito (alguns exemplos são McMaster (1996), Axelrod \& Cohen (1999), Kelly\&Allison (1999), Bauer (1999) e Gleiser (2002)). O desafio do presente trabalho está em sintonia com o desses e de outros inúmeros autores que procuram mostrar como, na prática, as descobertas desta nova ciência podem orientar a tomada de decisão nas organizações.

Neste sentido, o objetivo central deste artigo é apresentar a Teoria da Complexidade - a qual pretende dar conta do fenômeno da auto-organização - como uma nova base científica para a atualização da prática administrativa. Considerando que tal assunto é relativamente novo, faz-se, inicialmente, uma breve explanação sobre o seu significado. Em seguida, sugere-se o que poderia ser chamado de "princípios de administração complexa". Tais princípios resultam de uma observação da dinâmica das organizações através dos conhecimentos a respeito dos "sistemas complexos adaptativos". Por fim, através de um estudo de caso, é demonstrado como tais princípios manifestamse na gestão de uma organização.

\section{METODOLOGIA}

O presente artigo representa parte dos resultados de uma pesquisa (Agostinho, 2001) que teve como objetivo a construção de uma abordagem gerencial inspirada nos novos conhecimentos científicos a respeito do processo de auto-organização. Por mais que os modelos oriundos da ciência da complexidade sejam, a princípio, aplicáveis a sistemas das mais variadas disciplinas, sua transposição não pode estar baseada apenas em exercícios intelectuais ou em analogias abstratas. Para que tais conhecimentos sejam mais úteis do que metáforas didaticamente interessantes é preciso que sua transferência para o universo das organizações seja mediada pela observação da realidade concreta. Daí a importância da pesquisa empírica.

Considerando que o objetivo deste trabalho é criar uma abordagem alternativa - e não testar a aplicabilidade de uma teoria já existente, o método de "estudo de caso" mostra-se o mais apropriado (Gummesson, 1991). Este permite formar uma visão mais completa da organização, considerando as correlações entre os diversos aspectos. Mais ainda, é possível perceber como as interações entre os diversos indivíduos ocorrem no detalhe, deixando transparecer suas motivações e conflitos mais genuínos. A partir daí, torna-se mais fácil compreender como certas circunstâncias emergem como 
"conseqüências impremeditadas" (Giddens,1989) e por vezes indesejadas. O estudo de um caso é capaz de mostrar as restrições, as escolhas, as mudanças de rumo, enfim, a história que faz daquela empresa um exemplar único, que lhe confere identidade. Porém, nem por isso deixa de ser possível encontrar semelhanças entre as histórias de outras empresas, as quais podem ser beneficiadas pelos conhecimentos gerados no estudo - ainda que a experiência estudada não tenha sido a delas.

Foi realizado, então, o acompanhamento, in loco, do caso da implantação de uma nova unidade fabril de uma grande empresa brasileira do ramo de bebidas. O motivo da escolha deste caso em particular foi a decisão da empresa de que suas novas unidades deveriam buscar modelos de gestão coerentes com a tendência ${ }^{1}$ a alternativas organizacionais calcadas em uma maior autonomia das equipes de trabalho. Este fato despertou o interesse para sua experiência, uma vez que oferecia a oportunidade de estudar, em tempo real, a construção de um sistema de gestão autônoma.

A pesquisa de campo foi dividida em quatro etapas. A primeira delas teve por objetivo conhecer o contexto em que seria construído o sistema de gestão da nova unidade. Esta etapa, que durou aproximadamente oito meses e coincidiu com o primeiro semestre de operação da planta, caracterizou-se pela participação em um seminário interno para discussão de um esboço do sistema e pela realização de entrevistas ocasionais com o Gerente Geral. Foram coletadas, naquele momento, informações sobre a indústria e a tecnologia da empresa selecionada. Também foram pesquisados artigos na imprensa a respeito da companhia, de maneira a formar um melhor entendimento quanto ao seu contexto corporativo.

As etapas seguintes foram realizadas após o primeiro semestre de operação da unidade, quando sua rotina já se mostrava razoavelmente estabilizada. A pesquisa teórica, que era conduzida em paralelo, havia atingido um ponto em que o quadro conceitual já estava bem delimitado, apesar de extremamente abstrato. Parecia, então, que já era hora de partir para um convívio mais assíduo no local da pesquisa. A segunda etapa da pesquisa de campo teve início com visitas às áreas operacionais para conhecer a planta e o processo produtivo. Três meses mais tarde, foi iniciada a terceira etapa, a qual se caracterizou pela realização de entrevistas e de "observação participante" (Thiollent, 1988). Durante os seis meses que se seguiram, freqüentamos regularmente a fábrica, participando de reuniões ou acompanhando a produção. A etapa final foi marcada pela realização de um seminário, quando apresentamos à equipe da fábrica os principais conceitos referentes aos sistemas complexos adaptativos utilizados na pesquisa, bem como discutimos sua importância para compreendermos a realidade da organização.

Para dar suporte ao esforço de conjugar as reflexões teóricas sobre os "sistemas complexos adaptativos" com as observações derivadas do caso concreto, este trabalho recorre à teoria organizacional. Mais especificamente à obra de Herbert Simon, que compartilhava com a nova ciência da complexidade de uma visão sistêmica do mundo. A pesquisa empírica foi realizada, desta forma, tendo como orientação os conhecimentos oriundos do estudo dos "sistemas complexos adaptativos", porém, levando em consideração as especificidades das organizações.

\footnotetext{
${ }^{1}$ Percebida pela direção como sendo comum à grande parte das iniciativas empresariais bem sucedidas.
} 


\section{TEORIA DA COMPLEXIDADE: CONCEITOS GERAIS}

A palavra complexidade, em geral, traz à mente duas situações. A primeira é a de um quebracabeça com uma infinidade de peças. Como há um único lugar para cada peça, é possível, através da análise das peças e do grupamento daquelas semelhantes, simplificar o trabalho e montar o quebracabeça. Isto não parece ser "complexo", embora possa ser bastante "complicado". Entretanto, há casos em que poucos tipos de peças podem interagir umas com as outras de várias maneiras diferentes, produzindo uma infinidade de resultados. Um exemplo são as estruturas moleculares, as quais são formadas pela combinação de alguns poucos tipos de átomos. A identidade da molécula não se daria pelos tipos e quantidades dos átomos envolvidos, mas pelas ações que se estabelecem entre eles. Assim, "complexidade" é usada aqui em referência a esta segunda classe de fenômenos, para os quais a idéia-chave é interação (Morin, 1996, p.265).

Uma das principais características de tais fenômenos - os quais são objetos de estudo das novas ciências da complexidade - são as qualidades emergentes. Estas não surgem de regras complexas superiores nas quais já esteja embutido o resultado esperado. Ao contrário, resultam da interação de partes ou indivíduos movidos segundo algumas poucas e simples regras locais (que, dependendo do sistema considerado, podem tomar, por exemplo, a forma de leis da física, mecanismos metabólicos ou regras de conduta). Assim, uma vez que certas condições estejam presentes, a ordem pode emergir de situações aparentemente caóticas. Considere-se o exemplo da formação de cardumes e revoadas. Através de simulações, percebeu-se que estas complexas organizações podem se formar a partir do comportamento de cada peixe ou pássaro seguindo algumas poucas regras (embutidas em seus modelos mentais ou instintivos) como, suponha-se: tentar manter uma distância mínima dos outros objetos no ambiente, inclusive outros peixes ou pássaros; tentar manter a velocidade dos outros indivíduos em sua vizinhança e tentar mover-se em direção ao centro de massa dos outros indivíduos na vizinhança. Como observa Waldrop (1994, p.241), "o que era tão impressionante sobre estas regras era que nenhuma delas dizia, 'Forme uma revoada'. Ao contrário: as regras eram inteiramente locais, referindo-se somente ao que um indivíduo podia ver e fazer em sua própria vizinhança. Se uma revoada se formou, teria que ter sido de baixo para cima, como um fenômeno emergente".

Vem, então, a pergunta: de que maneira certas coisas - tais como moléculas, células, órgãos, cardumes ou cidades - conseguem manter uma coerência em situações de contínua mudança (variação de temperatura, ataque de vírus, morte de células, aparecimento de obstáculos ou vara de pescar, novas construções) sem que haja um planejamento central? Apesar das alterações que ocorrem tanto interna quanto externamente, tais coisas conseguem permanecer tempo suficiente para terem a elas atribuída uma identidade - uma "identidade agregada emergente", segundo Holland (1996, p.3). Identidade esta que reflete um padrão de interações entre seus constituintes, sejam eles átomos, moléculas, células, peixes, pessoas. Esta capacidade de agir de modo coerente é tida como a principal propriedade que caracteriza a emergência de "comportamento complexo" (Nicolis e Prigogine, 1989, p.13).

\section{Sistemas Complexos Adaptativos}

Uma vez compreendido o processo geral pelo qual os sistemas podem evoluir em níveis de complexidade crescente, resta olhar para dentro destes sistemas para procurar o que há em comum entre eles. O que permite colocar células, organismos, sociedades, organizações e ecossistemas dentro de uma mesma categoria? O que permite chamá-los todos de "sistemas complexos adaptativos" (segundo terminologia utilizada pelos cientistas ligados ao Instituto Santa Fé (Holland, 1996, p.4, GellMann, 1994, p.9)), ao mesmo tempo que excluímos desta classificação as estrelas e as galáxias?. 
Tais sistemas, embora diferindo no detalhe, possuem um tipo de dinamismo que os torna capazes de responder ativamente ao que ocorre ao seu redor, fazendo-os "qualitativamente diferentes de objetos estáticos tais como chips de computador ou flocos de neve, os quais são meramente complicados" (Waldrop, 1994, p.12). Estes objetos, tanto quanto estrelas e galáxias, são sistemas complexos, porém não-adaptativos. Eles não são capazes de aprender.

Para Gell-Mann (1994, p.17) a resposta está no fato de que "um sistema complexo adaptativo adquire informação sobre seu ambiente e sua própria interação com aquele ambiente, identifica regularidades naquela informação, condensando aquelas regularidades em um tipo de 'schema' ou modelo e agindo no mundo real com base naquele schema. Em cada caso, há vários schemata competindo e os resultados da ação no mundo real são retro-alimentados para influenciar a competição entre aqueles schemata".

A propriedade básica dos sistemas complexos adaptativos que é possível identificar nas palavras acima é a adaptação, no sentido de que o sistema é capaz de ajustar seu comportamento a partir do que consegue perceber sobre as condições do seu meio ambiente e sobre seu desempenho. O próprio termo "adaptativo" utilizado para qualificar este tipo de sistema evidencia tal propriedade.

No entanto, recorrendo-se à definição de "adaptação" utilizada por Holland (1996, p.9) - a qual está relacionada a "mudanças na estrutura (estratégia) com base na experiência do sistema" - não é possível deixar de considerar o aprendizado como uma propriedade determinante dos sistemas complexos adaptativos. Como define Plotkin (1994, p.251), “...convencionalmente, aprendizado é qualquer modificação de longa duração no comportamento devido à experiência..." Em resumo, diz-se que sistemas complexos adaptativos são sistemas que aprendem.

Apesar disso, aprendizado e adaptação apenas são capazes de dar conta da intrigante coerência exibida por estes sistemas mesmo em situações de profunda mudança? Afinal, é esta coerência que garante a permanência (ou a estabilidade) de um padrão que permite atribuir uma identidade ao sistema - uma identidade emergente, que não pode ser reconhecida nas partes, mas apenas no todo.

Observando-se, então, como Holland (1996, p.38) descreve um sistema complexo adaptativo:

"Sistemas complexos adaptativos são bastante diferentes da maioria dos sistemas que têm sido cientificamente estudados. Eles exibem coerência sob mudança, via ação condicional e previsão e eles fazem isso sem direção central. Ao mesmo tempo, parece que sistemas complexos adaptativos têm pontos de alavancagem, onde pequenas quantidades de input produzem grandes e direcionadas mudanças".

Exibir "coerência" sem "direção central" significa dizer que tais sistemas se auto-organizam, isto é, os padrões ordenados através dos quais se reconhece um organismo, uma sociedade ou um ecossistema emergem espontaneamente das interações entre os seus diversos componentes. Os comportamentos complexos em larga escala decorrem da organização ou agregação de agentes menos complexos, sem que precisem ser dirigidos externamente.

A possibilidade de auto-organização surge uma vez que os numerosos agentes que compõem o sistema são elementos ativos. Eles têm autonomia para orientarem suas ações de acordo com o que apreendem de sua interação com o ambiente - o qual em grande parte é formado pelos outros agentes. 
Em outras palavras, estes agentes estão livres para colocarem em prática sua capacidade de aprendizado e de adaptação.

Em resumo, sistemas complexos adaptativos são organizações em rede formadas por inúmeros agentes, os quais são elementos ativos e autônomos, cujo comportamento é determinado por um conjunto de regras e pelas informações a respeito do seu desempenho e das condições do ambiente imediato. Estes agentes aprendem e adaptam seus comportamentos a partir das pressões de seleção presentes. O comportamento global do sistema emerge, então, como efeito da combinação das interações (não-lineares) entre os diversos componentes.

Entretanto, o que parece mais interessante na descrição de Holland - além da relação entre coerência global e ação local - é a existência de "pontos de alavancagem" ou seja, pontos em que uma ação pode gerar efeito amplificador. Este é um aspecto de considerável importância quando se tem por objetivo intervir no comportamento de um sistema - como é o caso da administração. Assim como é possível, externamente, influenciar o sistema imunológico aplicando uma vacina, em se falando de organizações, espera-se também poder influenciar seu comportamento através de ações gerenciais dirigidas a certos pontos de alavancagem. Desta forma, o processo de autoorganização será gerenciado.

\section{A Organização Compreendida como um Sistema Complexo Adaptativo}

Esta visão da organização não é uma proposta nova. Décadas atrás, Herbert Simon - cuja obra tornou-se um clássico no estudo das organizações - já demonstrava ser apropriada a aplicação de imagens dos sistemas vivos para a compreensão das dinâmicas organizativas. Isto fica evidente, por exemplo, na introdução à terceira edição de "Administrative Behavior", quando ele define seu foco de atenção. Citando-o, então: "Neste volume olhamos mais atentamente os mecanismos de adaptação: como o processo de tomada de decisão e o sistema de comunicações servem de mediadores entre a organização e seu ambiente" (Simon,1976, p.xl). Prosseguindo nesta mesma edição, no capítulo XVI, por exemplo, - o qual se intitula "O nascimento de uma organização" - ele compara uma organização administrativa a organismos e os primeiros estágios de crescimento a um processo de "divisão celular". Emprega, ainda, expressões como 'seleção natural', 'coerência' ou 'emergir' - as quais são bastante familiares. Embora todo aquele volume contenha sinais de uma visão de organização como um sistema complexo adaptativo, foi escolhido, aqui, um pequeno trecho para representá-la:

"Mas enquanto a forma era previsível, certamente não foi planejada. O processo de multiplicação celular e de luta de poder dentro e em torno da agência [com referência à $E C A$ - o caso que apresenta] foram os principais processos através dos quais esta rápida adaptação e evolução de uma organização efetiva ocorreram" (Simon, 1976, p.332).

A obra de Simon antecipou a visão de organização como um "sistema complexo adaptativo", a qual viria a ser sugerida explicitamente pelos pesquisadores da nova ciência da complexidade. De Prigogine a Kauffman, passando por Holland e Gell-Mann, todos eles dedicam parágrafos ou mesmo capítulos inteiros de suas obras a este tema. Ainda assim, este não é o foco de seus estudos. Sua preocupação, de forma geral, é apenas a de indicar a abrangência de suas teorias, que podem ser aplicadas aos mais variados tipos de sistemas - inclusive organizações. Esse artigo aproveita, então, as pistas oferecidas por aqueles autores e avança sobre um terreno que parece ser bastante fértil para o florescimento de novas abordagens organizacionais. 


\section{A TEORIA DA COMPLEXIDADE COMO UMA NOVA BASE CIENTÍFICA PARA A ADMINISTRAÇÃO}

Considera-se que, em meados da década de 1980, o mundo dos negócios deu seu primeiro passo oficial em direção à Teoria da Complexidade, afastando-se mais ainda do paradigma mecanicista característico da Administração Científica de Taylor. A busca do recém criado Instituto Santa Fé por "um arcabouço teórico comum para a complexidade, capaz de iluminar tanto a natureza quanto a humanidade" (Waldrop, 1994, p.12), chamou a atenção do presidente da americana Citicorp logo que soube da iniciativa. Seu interesse estava na possibilidade do Instituto ajudá-lo a entender melhor a economia mundial - já que os esforços dos economistas profissionais não estavam sendo suficientes. Este homem - que crescera na Argentina e no Brasil e somara à sua formação em administração conhecimentos tanto das artes quanto das ciências - mostrava-se profundamente aberto para o novo e curioso a respeito de idéias acadêmicas. Não é de se espantar, portanto, que sua companhia tenha investido dinheiro no referido instituto em troca de "um novo modo de fazer as coisas em economia baseado no ponto de vista dos sistemas complexos adaptativos" (Waldrop, 1994, p.244).

Após alguns anos, começaram a aparecer os primeiros frutos dessa parceria. Em 1988, iniciouse o programa em economia do Instituto Santa Fé. Anos mais tarde, um de seus mais influentes cientistas - o biólogo Stuart Kauffman (1993, 1995) - criava uma joint-venture com a empresa de consultoria gerencial Ernst \& Young para aplicação da Teoria da Complexidade ao business. Chamado de "Bios Group", o empreendimento conta com dezenas de clientes, entre eles Unilever, Honda e General Motors ${ }^{2}$. Para aquelas empresas que querem conhecer mais sobre a Teoria da Complexidade antes de contratar os serviços especializados há a opção do "Praxis Group" do Instituto Santa Fé - um seminário sobre aplicações da Teoria da Complexidade nos negócios.

Além daqueles francamente interessados nas possibilidades da complexidade para administração e dos que observam de longe, acompanhando a literatura e os jornais, há os céticos. Suas críticas vão desde a ferramenta normalmente utilizada nas pesquisas de complexidade - a simulação por computador - e a dificuldade de verificação científica dos fatos até a suposta pretensão de ser uma teoria que explique tudo. A reserva com relação à nova abordagem é justificável, principalmente no mundo dos negócios onde a cada ano aparecem mais soluções e modismos gerenciais. De fato, a Teoria da Complexidade ainda está em construção. Não se sabe ao certo em que situações se aplica ou em que casos pode ser útil. Porém, mesmo assim, acredita-se que as pesquisas sobre complexidade são capazes de elucidar muita coisa que acontece no mundo real. Certamente, é impossível um modelo que se encaixe perfeitamente à realidade. Todavia, é preciso perfeição para orientar-se?

\section{PRINCÍPIOS DE ADMINISTRAÇÃO “COMPLEXA”}

Tomando por base o funcionamento geral dos sistemas complexos adaptativos, foram eleitos quatro conceitos-chave que definem a abordagem proposta neste artigo - autonomia, cooperação, agregação e auto-organização, os quais se relacionam da seguinte forma:

Indivíduos autônomos, capazes de aprender e de se adaptarem, cooperam entre si obtendo vantagens adaptativas. Tal comportamento tende a ser selecionado e reproduzido, chegando ao ponto em que estes indivíduos cooperativos se unem formando um agregado que também passa a se comportar como um indivíduo e assim por diante. Diz-se, então, que o sistema resultante se auto-organiza, fazendo emergir um

\footnotetext{
${ }^{2}$ Em matéria intitulada “A biologia do business”, publicada na Gazeta Mercantil de 27/11/1998, p.1. 


\section{comportamento global cujo desempenho também é avaliado por pressões de seleção presentes no ambiente (externo e interno).}

\section{Autonomia}

Autonomia é definida como sendo a faculdade do indivíduo orientar sua ação com base em sua própria capacidade de julgamento. Reconhecendo-se a possibilidade de incluir uma maior parcela dos membros da organização, antes simples executores de ordens, no papel de tomador de decisão, exercitando seu julgamento, as vantagens da autonomia tornam-se evidentes:

\section{Adaptabilidade}

Quando se abre mão da estrutura clássica de controle e se diminui o número de níveis hierárquicos, aparecem as primeiras vantagens da autonomia: menor custo e maior agilidade e, portanto, maior adaptabilidade. Menor custo pois: 1) reduz drasticamente o número de pessoas em cargos de comando que, teoricamente, ganham mais e 2) diminui o número de atividades que não agregam valor ao produto. Maior agilidade pois: 1) diminui o número de pessoas envolvidas e 2) aumenta a intensidade das relações entre as pessoas e, portanto, a velocidade e a qualidade das informações compartilhadas.

2. Aumento da diversidade

O convívio entre indivíduos autônomos permite o aparecimento do que poderia ser chamado de "mutação de idéias" - em analogia com as mutações genéticas que aumentam a diversidade e as chances de geração de alternativas viáveis. A autonomia garante a geração de idéias novas e sua sobrevivência até o momento de sua realização, quando então serão testadas e selecionadas. A autonomia é um mecanismo que permite a criação. Desta forma, novas soluções são inventadas, aperfeiçoadas e reproduzidas a todo instante, aumentando a variedade das soluções a serem selecionadas.

\section{Aprendizado}

Tanto indivíduos como organizações aprendem, no sentido de que são capazes de observar as conseqüências de seu comportamento e ajustar seus atos para atingir os propósitos desejados. Embora o aprendizado não seja privilégio dos seres humanos, estes e suas organizações apresentam uma considerável vantagem sobre os demais seres. A comunicação sofisticada e a capacidade de prever teoricamente as conseqüências de seus atos, sem que seja necessário experimentar uma situação real, resultam em uma enorme capacidade de aprendizado. Contudo, tamanho potencial só é realizado quando é permitido ao indivíduo colocar seu julgamento em ação, isto é, quando ele é autônomo.

\section{Redução de erros}

Outra grande vantagem da autonomia é que ela é erro-supressora. Indivíduos autônomos tendem a rever suas ações em função das dos demais ou mesmo comparar seus julgamentos a respeito de uma dada situação com os seus pares, corrigindo suas decisões. Com isso, uma grande quantidade de erros pode ser aceita sem comprometer o desempenho do sistema e, ao contrário, tornando-se até fontes de aprendizado e adaptação.

\section{Solução de conflitos}

Embora só existam porque há cooperação, as organizações são também palco para o conflito. Entretanto, ao contrário das estruturas rigidamente hierárquicas, os modelos organizacionais baseados na autonomia conseguem fazer com que o conflito seja resolvido local e imediatamente, evitando que tome maior vulto. As discórdias que não são logo tratadas pelos diretamente envolvidos tendem a se 
difundirem pela rede, contagiando outros agentes e dificultando o restabelecimento da cooperação. Estes indivíduos que recebem o conflito em segunda mão têm apenas um conhecimento parcial da origem da discórdia e, mais importante, da história das interações passadas entre os personagens principais - o que faz com que seja mais difícil ponderar e perdoar. Afastando-se da origem do conflito, será mais difícil contar com a confiança mútua para resolvê-lo.

\section{Cooperação}

A cooperação é um fator crítico para modelos de gestão que pretendam aproveitar o conhecimento disperso na organização. Seria possível dizer, inclusive, que quanto maior a capacitação de seus integrantes, maior a necessidade da existência de uma cooperação espontânea (Agostinho, 1997). É a cooperação entre indivíduos de uma equipe, ou mesmo entre equipes, que permite o fluxo de conhecimentos capaz de contribuir para o desempenho da organização.

Uma vez que se duvide da onisciência da administração clássica (segundo a qual haveria sempre um conjunto de meios aguardando para ser conhecido cientificamente pelo administrador e, assim, atingir um determinado fim), também será questionado o seu poder para impor uma cooperação durável. É então que a teoria da cooperação de Axelrod (1990) aponta um caminho alternativo. Aquele autor defende que a cooperação pode emergir, sem a presença de autoridade central ou de forças coercitivas, a partir de indivíduos que buscam seu próprio benefício. O incentivo para cooperar está na percepção de que é possível a obtenção de ganhos através da ajuda mútua, ou melhor, que o desempenho de cada um pode ser superior ao que seria possível caso não contasse com a cooperação dos demais. Entretanto, para que um ambiente seja propício para a evolução da cooperação é preciso que sejam observadas certas condições:

1. Os indivíduos devem interagir de forma continuada, sendo um encontro futuro algo muito provável.

2. Eles devem ser capazes de se reconhecerem mutuamente, lembrando a história de seus encontros passados.

3. Suas relações devem ser suficientemente simétricas de forma a garantir a existência de reciprocidade.

$\mathrm{Na}$ reciprocidade entre indivíduos que buscam o interesse próprio está a chave para este tipo de cooperação. Tanto a cooperação quanto a oposição podem ser retribuídos. Estando atento aos sinais do outro, um indivíduo pode ajustar o seu comportamento, provocando novas adaptações no padrão de ações do outro. Nas palavras de Axelrod (1990, p.123), “O truque é encorajar essa cooperação. Uma boa maneira de fazer isto é deixar claro que você vai retribuir. Palavras podem ajudar aqui, mas como todos sabem, atos falam mais alto que palavras."

\section{Agregação}

Uma organização, ou um agregado, pode ser identificado por seus objetivos e competências, uma vez que em torno dos objetivos globais agrega-se um certo número de indivíduos que contribuem com seus conhecimentos e habilidades para a competência do todo. Da mesma forma que um objetivo pode ser desdobrado em sub-objetivos, a organização é dividida em subsistemas com seus respectivos objetivos. A estrutura da organização toma, então, uma forma hierárquica - comum aos sistemas complexos adaptativos em geral -, com os agregados dispostos em níveis sucessivos. Quanto mais complexo o sistema, mais níveis de organização serão encontrados. 
O fato de ser uma estrutura hierárquica não implica que tenha de ser conduzida burocrática ou autoritariamente. A questão não está na forma de organização, mas na maneira como são estabelecidos os limites à ação autônoma: através de uma restrição externa (poder coercitivo, por exemplo) ou através dos próprios limites de competência que impediriam o julgamento adequado. Se, por qualquer razão, lhe falta informação, habilidade para discernir ou ainda interesse em decidir é sinal de que o limite da sua autonomia foi atingido e, a partir daí, as ações são orientadas por indivíduos em um outro nível na hierarquia.

Por ambos os caminhos depara-se com as fronteiras de um agregado, as quais devem ser entendidas como aquelas que definem o universo de ação autônoma. A partir destas fronteiras, as ações são orientadas externamente, isto é, por indivíduos que fazem parte de um nível de agregação superior. Tais fronteiras sempre existirão, sejam elas estabelecidas rígida e autoritariamente ou como resultado da própria postura dos componentes do agregado. Contudo, convém observar que não se está considerando o caso em que um determinado grupo se julga capaz de agir autonomamente, apesar de não ter, de fato, competência suficiente. Nessa situação, ou o nível superior impõe sua autoridade tentando garantir o bom desempenho daquele grupo ou este ficará à mercê das pressões de seleção que existam em seu ambiente.

\section{Auto-organização}

Talvez um dos aspectos mais interessantes que diferenciam as organizações sociais humanas dos demais sistemas complexos adaptativos seja a possibilidade que nós, seres humanos, temos de escolher como elas devem operar na prática. Graças à nossa consciência podemos dar cores à "mão invisível", usando racionalmente nossos maiores ou menores poderes de influência. Exercitamos esta capacidade quando, por exemplo, definimos o perfil ideal dos membros da organização (competências, personalidade, história pessoal) ou quando estimulamos certas relações (favorecendo o contato, criando situações que exijam ação conjunta). Reconhecendo as conexões por onde ocorrem os fluxos mais relevantes e identificando os pontos com maior ou menor efeito multiplicador, é possível direcionar os recursos - sejam eles de informações, conhecimentos, materiais ou confiança, para citar alguns - mais adequadamente.

Ao atuarem dessa forma, os administradores (ou agentes gerenciais) criam as condições iniciais a partir das quais o sistema se auto-organiza. Estabelece-se, assim, uma estrutura mínima a partir da qual emerge a organização.

Porém, ao fazerem isso, são reduzidos os graus de liberdade do sistema, diminuindo as margens de manobra necessárias quando os problemas aparecem. Portanto, para garantir a flexibilidade e adaptatividade do sistema, a estrutura deve ser apenas minimamente definida, não especificando "nada além do mínimo necessário para que uma atividade em particular ocorra” (Morgan, 1993, p.363). É necessário ter o cuidado, por exemplo, ao se estabelecerem as qualidades requeridas para os membros de uma organização, de não comprometer a diversidade - a qual se torna tanto mais necessária quanto mais complexo for o ambiente em questão. Ademais, lembre-se que, quando alguém com outros atributos vem ocupar uma posição, são criadas novas ligações na rede, alterando o padrão de relacionamentos e gerando mais diversidade.

Portanto, caso os indivíduos influentes de uma organização queiram tirar proveito do potencial auto-organizante desses sistemas, sua atuação estará voltada para a geração das condições propícias para isso, afastando-se da prescrição e do controle. Considerando que o desempenho global é 
conseguido a partir da coerência das ações de indivíduos que cooperam entre si, tais condições se referem àquelas capazes de:

- Atrair indivíduos com competências relevantes e permitir que tenham autonomia para utilizá-las.

- Estimular o surgimento de um padrão de relações predominantemente cooperativas.

- Fazer com que as percepções individuais sejam mutuamente compartilhadas, promovendo o aprendizado conjunto.

- Garantir que o resultado das ações seja reportado aos atores e que estes sejam capazes de compreendê-lo e de ajustarem seu comportamento. Em outras palavras, garantir a eficiência e eficácia do feedback.

Assim, o foco da Administração Complexa concentra-se em quatro eixos fundamentais: autonomia, cooperação, agregação e auto-organização. Portanto, o papel dos líderes em todos os níveis - isto é, dos agentes gerenciais - é o de criar e manter as condições propícias para que:

1. Os indivíduos tenham o direito e que sejam capazes de agir com autonomia. Todas as ações que, direta ou indiretamente, estimulem e legitimem a participação e melhorem a capacidade de julgamento estarão cumprindo esta função.

2. Os indivíduos reconheçam as situações em que vale a pena cooperar - tanto com seus pares como com a organização - e o façam, não porque são coagidos, mas por entenderem que assim devem se comportar. Ações gerenciais que favoreçam a durabilidade e a intensidade das relações e ainda garantam a simetria necessária para que as ações de cada um sejam tratadas com reciprocidade por aqueles com quem convive e co-evolui contribuem para que a cooperação emerja sem a necessidade de uma autoridade central. Reconhece-se, assim, o princípio da autonomia.

3. Os indivíduos conheçam não só as restrições existentes para a realização do objetivo em torno do qual se agregam, como também suas implicações para a realização dos objetivos mais globais do sistema. É fundamental, também, que sejam fornecidas condições para que o agregado desenvolva suas competências, tanto atraindo e selecionando talentos quanto incentivando o aprendizado contínuo.

4. O sistema se auto-organize, não só abrindo e fortalecendo canais de comunicação multidirecionais, como também ampliando a capacidade de percepção, interpretação e resposta a todos os tipos de feedback.

\section{ADMINISTRAÇÃO COMPLEXA NA PRÁTICA: O ESTUDO DE CASO}

Havia, na empresa pesquisada, a crença de que profissionais mais talentosos e qualificados tenderiam a contribuir mais para o sucesso da empresa. Entretanto, a prática mostrava que isto nem sempre era verificado. Uma de suas fábricas mais modernas, que seguiu à risca o critério de seleção que exigia qualificação de no mínimo segundo grau técnico completo para operadores e nível superior completo para orientadores, além de não apresentar a produtividade esperada, sofria com uma alta taxa de turnover. Chegou-se então à conclusão de que uma maior qualificação dos indivíduos não era garantia de um desempenho global excelente. As vantagens de uma melhor formação educacional e 


\section{profissional só são conseguidas quando o conhecimento é utilizado no exercício do julgamento - ou seja, na ação autônoma. Para isso é necessário um sistema de gestão apropriado.}

Foi nesse contexto que o Sistema de Gestão Autônoma (SGA) - como viria a ser conhecido começou a ser concebido, tão logo a construção da fábrica foi iniciada, no início de 1997. Todos os gerentes tomaram para si a responsabilidade de desenvolver um modelo organizacional capaz de criar condições para que a autonomia fosse a base para o sucesso da unidade. No início da operação, em julho de 1998, a fábrica já contava com o seu "Sistema de Gestão Autônoma" formalizado. O resultado foi um modelo de gestão baseado na ação de equipes autônomas, onde:

- As equipes de operação assumem o gerenciamento da rotina do seu negócio em todas as suas dimensões, incluindo qualidade, custo, atendimento, moral, segurança e meioambiente.

- Os supervisores dão lugar aos "orientadores" que desempenham um papel de conselheiro e professor nas questões operacionais. Sua responsabilidade transfere-se para a gestão do processo ou da unidade gerencial básica sob sua responsabilidade, focando em projetos de melhoria e na resolução de problemas.

Em linhas gerais, podemos dizer que o Sistema de Gestão Autônoma estabelece uma "estrutura mínima" para que surjam condições iniciais capazes de promover a autonomia, possibilitando a emergência de processos auto-organizativos. Tal estrutura é caracterizada por:

\section{- Indicadores do Grau de Autonomia \\ - Critérios para Seleção \\ - Critérios para Promoção \\ - Sistema de Comunicação}

Criados como instrumento para acompanhamento gerencial dos progressos na implantação do Sistema de Gestão Autônoma, os indicadores do grau de autonomia tornaram-se uma ferramenta para conscientização. Mensalmente, orientadores e operadores de suas respectivas equipes reúnem-se para avaliar o grau de autonomia que atingiram. Para isso, eles contam com a ajuda de um documento que estabelece uma escala de pontuação para medir o grau em que decisões operacionais contam com a participação do orientador.

O Sistema de Gestão Autônoma também é caracterizado por um conjunto de critérios para promoção, os quais incluem indicadores relacionados tanto ao desempenho da equipe quanto ao desempenho individual, em aspectos como qualidade, custo, moral e segurança. Isto reflete a preocupação em retribuir o esforço por uma ação autônoma em todos os aspectos que impactam sobre o desempenho das equipes e dos processos pelos quais são responsáveis.

Da mesma forma são estabelecidos critérios para seleção, os quais representam o perfil de pessoal desejado para desempenhar os diversos papéis na unidade. Foi criado um documento - que é continuamente reavaliado - capaz de estabelecer, de forma detalhada, os conhecimentos, habilidades $e$ atitudes para cada área, para cada função. Tal instrumento - chamado internamente de "CHA" - é freqüentemente consultado, não só pela área de gestão de pessoas, como também por indivíduos de todas as áreas, uma vez que todos participam do processo de seleção de novos membros para suas equipes. 
Por fim, o Sistema de Gestão Autônoma apóia-se sobre um sistema de comunicação que estabelece uma rotina detalhada de reuniões. Tanto para aquelas com freqüência diária - como as reuniões de troca de turno ou as reuniões de produção - quanto para as anuais - como é o caso da reunião de desdobramento de diretrizes. O sistema define claramente os objetivos, quem deve participar (embora, a princípio, todas as reuniões sejam abertas a qualquer um que queira tomar parte) e o tempo máximo de duração (em média, 30 minutos). Com isso, espera-se que seja mantido o foco nas questões relevantes, garantindo a produtividade dessas reuniões.

Nota-se que os quatro itens sobre os quais se fundamenta o sistema de gestão desenvolvido pela fábrica estudada demonstram a atenção aos quatro aspectos considerados críticos para uma organização entendida como um sistema complexo adaptativo: autonomia, cooperação, agregação e autoorganização, como está representado no quadro a seguir.

Quadro 1. Compatibilidade entre o "Sistema de Gestão Autônoma" e os princípios da "Administração Complexa".

\begin{tabular}{|c|c|}
\hline Sistema de Gestão Autônoma & Administração Complexa \\
\hline $\begin{array}{l}\text { - } \text { Indicadores do Grau de Autonomia } \\
\text { - Critérios para Promoção } \\
\text { - Critérios para Seleção } \\
\text { - Sistema de Comunicação }\end{array}$ & $\begin{array}{l}\text { - Autonomia } \\
\text { - Cooperação } \\
\text { - Agregação } \\
\text { - Auto-Organização }\end{array}$ \\
\hline
\end{tabular}

A intervenção exercida pela direção da organização ocorre no sentido de promover as condições para que esta manifeste a capacidade de se auto-organizar - característica dos sistemas complexos adaptativos. A partir da definição de uma estrutura mínima (no caso representada pelos quatro subsistemas mencionados), a direção pretende estimular a autonomia, a cooperação, a agregação competente e a auto-organização.

O acompanhamento regular de indicadores do grau de autonomia contribui para promover a autonomia, tanto por legitimá-la quanto por defini-la em termos concretos. Por sua vez, os critérios de promoção procuram deixar claras as regras para o alcance de grande parte dos benefícios que um indivíduo espera obter ao fazer parte de uma organização. Assim, ao estabelecer critérios oficiais de promoção, a unidade favorece a cooperação tanto por mostrar com clareza sua estratégia a este respeito quanto por retribuir o empenho de seus colaboradores com ganhos concretos. Os critérios de seleção, por outro lado, servem para orientar o processo de agregação no sentido de fazer com que os novos integrantes tragam, de fato, benefícios para a organização. Para garantir que a organização seja capaz de se auto-organizar - resolvendo problemas localmente sem que seja necessária, a todo instante, a intervenção de um poder superior -, o Sistema de Gestão Autônoma conta com um sistema de comunicação. Através dele amplia-se a competência global, seja pela troca de conhecimentos entre os indivíduos, seja pelas possibilidades de feedback geradas. Em outras palavras, ao desenvolver este modelo de gestão, a fábrica estudada espera que um sistema de comunicação eficiente permita que indivíduos autônomos e competentes atuem cooperativamente, lançando mão de sua capacidade de julgamento e de aprendizado, para garantir o sucesso da organização.

O primeiro ano de operação foi suficiente para comprovar a superioridade do sistema gerencial implantado. O excelente desempenho desta nova unidade ficou evidente através dos mais diversos indicadores. Ainda durante o processo de instalação da fábrica, o sistema contribuiu para que fossem 
cumpridas, com folga, as metas de prazo e orçamento. Alguns meses mais tarde, já em operação, destacava-se como a segunda unidade da companhia com o menor custo variável. Mais ainda, em 9 dos 12 meses do ano de 1999, o produto desta unidade foi considerado "produto padrão" da companhia, ressaltando sua excelência em qualidade intrínseca.

Entretanto, o sistema não estava robusto o suficiente para sobreviver ao seu próprio sucesso. Dois anos mais tarde, não havia mais qualquer pessoa do quadro executivo original. $O$ excelente desempenho desta unidade colocou seus profissionais em evidência, provocando sua transferência para outras unidades. Hoje, a fábrica estudada não vive mais seus dias de glória. Seu desempenho mostrase bastante comprometido (segundo inúmeros indicadores internos) em comparação a outras unidades da companhia, muito embora ainda tenha os equipamentos modernos e uma mão-de-obra bem qualificada.

\section{CONCLUSÃO}

Seja na perspectiva da administração clássica ou da "Administração Complexa", a principal tarefa do administrador continua a mesma: através da ação diretiva, tentar "determinar" um rumo para o sistema, de acordo com o interesse dos indivíduos que ela representa. Entretanto, o conhecimento a respeito dos sistemas complexos adaptativos traz implicações significativas para a ação gerencial.

- Em primeiro lugar, põe um fim na ilusão de que seja possível determinar exatamente o desempenho de um sistema, muito embora se mantenha a esperança de influenciá-lo.

- Segundo, uma vez reconhecida a existência de um comportamento complexo e autônomo inerente ao sistema, o tipo de ação diretiva da administração é consideravelmente alterado. Esta deixa de se concentrar na prescrição e no controle, passando à tarefa de promover as condições para que o desempenho emergente seja o mais próximo possível do desejado.

A abordagem aqui proposta tem por finalidade chamar a atenção dos administradores para alguns pontos de alavancagem - onde os esforços em gerar as condições propícias para a autoorganização são recompensados com um desempenho superior. Tais pontos formam os pilares do que é chamado aqui de "Administração Complexa": autonomia, cooperação, agregação e auto-organização. As formas de gerar condições que promovam esses quatro elementos críticos são inúmeras. Não há uma estratégia única ou um roteiro geral para implantação do modelo. Por isso, é necessária a compreensão do significado de cada um desses conceitos, tanto na perspectiva dos sistemas complexos quanto das organizações em particular.

O caso aqui apresentado ilustra como pode ser simples a aplicação de uma abordagem complexa para a administração, caso se conheça bem o negócio que se tem em mãos. A partir de algumas poucas ações é possível criar uma estrutura em que cada integrante da organização consiga exercer sua autonomia e, ainda assim, agir em coerência com o grupo. O Sistema de Gestão Autônoma nada mais é do que um conjunto de algumas poucas regras simples, facilmente compreendida por cada indivíduo, concebido de tal forma que fosse possível:

- O estímulo à ação autônoma,

- A evolução espontânea de um padrão de relações cooperativo,

- A agregação de pessoas capazes de contribuir para a competência do conjunto e 
- A emergência de um desempenho organizacional superior, a partir de competências diversas e dispersas pela organização.

Entretanto, fica evidente a fragilidade do sistema. O modo de gerenciar que permitiu que a fábrica estudada obtivesse seus excelentes resultados foi comprometido por seu próprio sucesso. Enquanto não é sistematizada e plenamente praticada, uma abordagem gerencial tem sua capacidade de reprodução limitada à memória e conduta dos indivíduos fundadores. Ademais, considerando que iniciativas de gestão autônoma como esta não têm respaldo na tradição administrativa, o descrédito pode levar facilmente à sua descontinuidade.

A desconfiança com relação a abordagens gerenciais autônomas não é sem fundamento. Quando se fala de sistemas gerenciais que lançam mão de uma maior autonomia dos indivíduos, devese estar ciente, em primeiro lugar, da incerteza associada à própria ação autônoma. Embora suscetível à influência externa, a decisão final de um indivíduo ocorre em função de seu julgamento no momento crítico.

Paradoxalmente, neste quadro de incerteza e complexidade crescentes, tão comum às organizações contemporâneas, ainda tenta-se, ingenuamente, dirigir e controlar tudo de cima. Apesar de toda a incerteza que existe, não parece que contar com a auto-organização seria uma alternativa mais razoável para a ação gerencial?

Mesmo assim, deve-se reconhecer que a principal tarefa da administração segundo a abordagem aqui proposta não é trivial. A forma de poder da liderança altera-se, tornando-a mais sutil, porém não menos intensa. Ao passar a atuar sobre as premissas decisórias de indivíduos autônomos, o administrador - ou o agente gerencial - precisa desenvolver novas competências e aprofundar e renovar continuamente seus conhecimentos. Seu poder deixa de contar exclusivamente com a legitimidade de sua posição, exigindo muito mais do seu talento.

O desafio associado à Administração Complexa reflete o paradigma científico que a inspira. Enquanto o paradigma newtoniano transmitia ao administrador clássico a segurança de que um mecanismo bem projetado terá bom desempenho se for bem operado, as idéias de Darwin lembram ao administrador "complexo" que, por mais que ele faça a sua parte, os rumos da organização dependerão de um contínuo jogo com o ambiente. O desempenho da organização está associado à sua capacidade de se adaptar às condições que se apresentem a cada momento. Provavelmente, alguns administradores ainda não estejam preparados para ver o poder de organizar sair de suas mãos em direção a uma "mão invisível". No entanto, acredita-se que aqueles que se disponham a arriscar nesta alternativa venham a ser recompensados.

\section{Artigo recebido em 29/09/2001. Aprovado em 09/09/2002.}




\section{BIBLIOGRAFIA}

AGOSTINHO, M. Trabalho em Equipe e a Evolução da Cooperação, Rio de Janeiro, anais do V Encontro Nacional da ABET (Associação Brasileira de Estudos do Trabalho), 1997.

Agostinho, M. A Organização Emergente: Gerenciando o Processo de Auto-Organização, Rio de Janeiro, Tese de Doutorado apresentada ao Programa de Engenharia de Produção da COPPE, Universidade Federal do Rio de Janeiro, 2001.

AXELROD, R. The Evolution of Cooperation, London: Penguin Books, 1990.

AXELROD, R., COHEN, M. Harnessing Complexity: organizational implications of a scientific frontier, New York: The Free Press, 1999.

BAUER, R. Gestão da Mudança: Caos e Complexidade nas Organizações, São Paulo, Editora Atlas, 1999.

GELL-MANN, M. The Quark and the Jaguar: Adventures in the Simple and the Complex, New York: W. H. Freeman and Company, 1994.

GIDDENS, A. A Constituição da Sociedade, São Paulo: Martins Fontes (do original (1984) The Constitution of Society), 1989.

GLEISER, I. Caos e Complexidade: A Evolução do Pensamento Econômico, Rio de Janeiro, Editora Campus, 2002.

GUMMESSON, E. Qualitative Methods in Management Research, Newbury Park, California, Sage Publications, 1991.

HOLLAND, J. H. Hidden Order: How Adaptation Builds Complexity, edição em paperback, s.1.: Helix Books, 1996.

KAUFFMAN, S. A. The Origins of Order: Self-Organization and Selection in Evolution, New York: Oxford University Press, 1993.

KAUfFMAN, S. A. At Home in the Universe: The Search for Laws of Self-Organization and Complexity, New York: Oxford University Press, 1995.

KELLY, S., ALliSON, M. A. The Complexity Advantage, New York: McGraw-Hill, 1999.

McMASTER, M. D. The Intelligence Advantage: Organizing for Complexity, Boston: ButterworthHeinemann, 1996.

MORGAN, G. "Organizational Choice and the New Technology". In: The Social Engagement of Social Science: A Tavistock Anthology, vol. II: The Socio-Technical Perspective, Philadelphia: University of Pennsylvania Press, pp. 354-368, 1993. 
MORIN, E. Ciência com Consciência, Rio de Janeiro: Bertrand Brasil ( do original (1982) - revisto em 1990 - Science avec Concience), 1996.

NICOLIS, G., PRIGOGINE, I. Exploring Complexity, New York: W. H. Freeman and Company, 1989.

PLOTKIN, H. Darwin Machines and the Nature of Knowledge, London: Penguin Books, 1994.

SIMON, H. A Administrative Behavior, $3^{\text {a }}$ edição expandida com nova introdução, New York: The Free Press, 1976.

THIOLlENT, M. Metodologia de Pesquisa-Ação, 4 a edição, São Paulo, Cortez Editora, 1988.

WALDROP, M. M. Complexity: the Emerging Science at the Edge of Order and Chaos, London: Penguin Books, 1994. 